\title{
O DIREITO À SAÚDE COMO DIREITO HUMANO E FUNDAMENTAL
}

\author{
THE RIGHT TO HEALTH AS HUMAN AND \\ FUNDAMENTAL LAW
}

\author{
Marcelo Lamy ${ }^{1}$ \\ Rosilma Roldan ${ }^{2}$ \\ Milton Marcelo Hahn ${ }^{3}$
}

Data de recebimento: $26 / 04 / 2018$

Data de Aprovação: 02/08/2018

\section{RESUMO}

Este trabalho visa a contribuir para uma visão mais ampla sobre o direito à saúde, como direito humano e fundamental, indissoluvelmente ligado ao direito à vida e ao direito à integridade física. Este estudo, realizado por meio

\footnotetext{
1 Professor Permanente e Vice Coordenador do Programa de Pós-Graduação Stricto Sensu em Direito da Saúde da Universidade Santa Cecília. Líder do Grupo de Pesquisa CNPq "Direitos Humanos e Desenvolvimento Sustentável". Coordenador do Laboratório de Políticas Públicas da Universidade Santa Cecília. Coordenador do Projeto Respirando Vida (Universidade Santa Cecilia). Advogado. Doutor em Direito Constitucional (PUC-SP). Mestre em Direito Administrativo (USP). Bacharel em Direito (UFPR). Instituição de origem: Universidade Santa Cecília.

E-mail: marcelolamy@unisanta.br

\begin{abstract}
2Pesquisadora. Membro do Grupo de Pesquisa CNPq "Direitos Humanos e Desenvolvimento Sustentável". Mestranda em PESP). Instituição de origem: Universidade Santa Cecília. Instituição financiadora: CAPES.

E-mail: rosilmaroldan@gmail.com
\end{abstract} Direito da Saúde (Universidade Santa Cecília). Membro do Projeto Respirando Vida (Universidade Santa Cecília). Advogada. Vice-Presidente da Comissão de Direito da Saúde da OAB/Santos-SP. Especialista em Direito Penal e Direito Público (ESM-
}

\begin{abstract}
${ }^{3}$ Advogado. Mestrando em Direito da Saúde pela Universidade Santa Cecília. Pós-Graduando em Economia e Gestão de Saúde pela Faculdade de Saúde Pública (USP). Secretário do Conselho Municipal de Saúde de Santos. Presidente da Comissão de Direito da Saúde da Ordem dos Advogados do Brasil Subseção de Santos. Membro Titular da Comissão Nacional de Ética em Pesquisa - CONEP. Membro do Grupo de Pesquisa CNPq "Direitos Humanos e Desenvolvimento Sustentável" (Unisanta). Assessor da Presidência do Tribunal de Ética e Disciplina XIV Turma da OAB/SP.

E-mail:mmhahn@gmail.com
\end{abstract}


de pesquisa bibliográfica, procurou conceituar e distinguir direitos humanos, direitos fundamentais, para, em seguida, buscar o direito à saúde como direito humano e fundamental, como corolário do direito à vida e integrado ao meio ambiente equilibrado e à sustentabilidade. Este artigo traz, também, legislação específica e a visão internacional sobre o direito à saúde, como direito social, a exigir atuação protetiva estatal.

\section{PALAVRAS-CHAVE}

Direitos Humanos; Direitos Fundamentais; Direito à Vida; Direito à Saúde. Direito à Integridade Física.

\section{ABSTRACT}

This paper aims to contribute to a broader view on the right to health, as a human and fundamental right, indissolubly linked to the right to life and the right to physical integrity. This study, carried out through bibliographical research, sought to conceptualize and distinguish human rights, fundamental rights, and then seek the right to health as a human right and fundamental, as a corollary of the right to life and integrated into the balanced environment and the sustainability. This article also brings specific legislation and the international vision on the right to health, as a social right, to require state protective action.

\section{KEYWORDS}

Human rights; Fundamental rights; Right to life; Right to Health. Right to Physical Integrity. 


\section{INTRODUÇÃO}

Os direitos humanos atingiram seu ápice no período republicano, no Brasil, quando a maior preocupação era com a intromissão estatal no exercício dos direitos individuais e civis. Propugnava-se pelo afastamento do Estado para que, com suas ações arbitrárias, não interferisse na vida do cidadão, prejudicando-lhe a liberdade e a iniciativa.

Com o incremento das relações comerciais, sociais e culturais, os direitos evoluíram e adaptaram-se às novas necessidades do cidadão - aos direitos individuais e civis, agregaram-se os direitos sociais, culturais e econômicos, sendo considerado o direito à saúde um dos direitos sociais.

Os direitos fundamentais são os direitos humanos positivados no ordenamento jurídico do país, preferencialmente contemplados na Constituição Nacional. $\mathrm{O}$ direito à saúde, corolário do direito à vida e do direito à integridade física, tem sido contemplado em quase todas as Constituições dos países e na maioria dos tratados e pactos internacionais.

O objetivo dessa pesquisa é o de investigar o que há em matéria de doutrina e legislação nacional, assim como firmar conceitos, baseados na visão nacional e internacional, no que diz respeito ao direito à saúde, à integridade física e ao direito à vida, como direitos humanos e fundamentais.

A metodologia utilizada foi a pesquisa bibliográfica, com consulta a juristas, doutrinadores, autores especializados, e pesquisa à legislação nacional, aos pactos e aos tratados internacionais.

\section{OS DIREITOS HUMANOS, FUNDAMENTAIS E À VIDA}

Os direitos humanos, como nos ensina Ramos (2017), consistem em um conjunto de direitos considerados indispensáveis para uma vida humana pautada na liberdade, igualdade e dignidade. Os direitos humanos são os direitos essenciais e indispensáveis à vida digna.

Sarlet (2017) nos alerta para o fato de que, em vários contextos, são utilizadas, indistintamente, as expressões como direitos humanos, direitos do homem, direitos subjetivos públicos, liberdades públicas, direitos individuais, 
liberdades fundamentais, que seriam categorias mais limitadas do que o amplo universo abrangido pelo que chamamos de direitos fundamentais:

(...) ao passo que, no âmbito da filosofia política e das ciências sociais de um modo geral, bem como no plano do direito internacional, a expressão mais utilizada siga sendo a de direitos humanos, no domínio do direito constitucional (...) a opção terminológica pelos direitos fundamentais acaba sendo a mais afinada com o significado e conteúdo de tais direitos na Constituição, para além do fato, já referido, de que se cuida da terminologia adotada pelo próprio constituinte brasileiro (SARLET, 2017, p. 302-303).

As expressões direitos do homem e direitos fundamentais são, muitas vezes, empregadas como sinônimas. Segundo a sua origem e significado, podemos defini-las assim: direitos do homem, como aqueles direitos válidos para todos os povos, em todos os tempos (dimensão jusnaturalista-universalista); e direitos fundamentais, como os direitos do homem, jurídico-institucionalmente garantidos e limitados espaço-temporalmente.

Os direitos do homem viriam da própria natureza humana e, por isso, seriam invioláveis, atemporais e universais; e os direitos fundamentais seriam os direitos objetivamente vigentes, numa ordem jurídica concreta (CANOTILHO, 1991, p. 529).

No início da República, em que a preocupação com os direitos do ser humano começou a ampliar-se significativamente, a ênfase era sobre os direitos individuais e civis e a limitação da atividade estatal, os chamados direitos de resistência, frente às possíveis arbitrariedades que pudessem ser cometidas pelo Estado, no exercício desses direitos.

Com o desenvolvimento das relações econômico-sociais, a preocupação com os direitos humanos também evoluiu para um novo patamar, que envolvia direitos sociais, culturais e econômicos, a não exigir a ausência, o afastamento do Estado, mas, pelo contrário, sua presença e proteção em tais relações, direitos esses que se vieram acumular aos direitos individuais e civis.

A evolução das tecnologias, os conflitos internacionais, as crises econômicas levaram os direitos humanos a uma nova evolução, agregando, aos 
direitos já existentes, os direitos da fraternidade ou de solidariedade. David Araújo e Serrano Nunes Júnior (2017) nos lembram de que:

A denominação Direitos do Homem ou Direitos Humanos acumularam, ao longo da história, um significado próprio e distinto do que se pretende apontar. A locução indica predicados inerentes à natureza humana e, enquanto tais, independentes de um sistema jurídico específico, mas de uma dimensão ingênita e universalista (DAVID ARAÚJO; SERRANO NUNES JÚNIOR, 2017, p. 150).

Não há dúvida de que os direitos fundamentais são direitos humanos, pois sua titularidade é sempre do ser humano, mesmo que representado por coletividades ou grupos, mas a distinção deve ser feita, considerando o contexto do direito constitucional positivo.

O desejo mais importante da humanidade, o primeiro, o maior, o que, realmente, define seu caráter de ser humano, é a liberdade. Todos a querem, precisam dela, tanto a pessoal, como a de espírito, assim também a liberdade econômica e a liberdade de política. É por meio dela que os seres humanos confirmam sua humanidade, porque podem escolher, na medida em que criam ideias e comportamentos novos, sem limitar-se a imitar ou obedecer a ideias e comportamentos dos demais.

Sendo assim a liberdade uma necessidade básica e pressuposto da humanização, as normas que devem garanti-la são chamadas de direitos fundamentais, ou fundantes, assim chamados porque nenhum outro direito existe sem eles. Uma sociedade civilizada parte da liberdade de seus cidadãos. A garantia de liberdade é um dos pressupostos de legitimidade de toda a ordem jurídica, na lição de Michael e Morlok (2016, p. 47), que colocam os direitos fundamentais entre os elementos nucleares de uma Constituição.

Os autores confirmam que o direito à justiça implica a igualdade da garantia desse mesmo direito e que "liberdade igual para todos os seres humanos é a essência do significado dos direitos fundamentais" (MICHAEL; MORLOK, 2016, p. 48).

Os direitos fundamentais não são contra qualquer pessoa, mas contra o 
Estado e contra os obstáculos à liberdade controlados pelo Estado. O entendimento clássico dos direitos fundamentais está na prevenção, ou na limitação, da interferência do Estado na vida de cada cidadão.

Como o ser humano é um ser social, os direitos fundamentais nunca podem ser considerados isoladamente, mas sempre relativizados aos demais direitos. Por essa razão, a liberdade de um tem limite na liberdade dos outros e nos interesses da sociedade. $\mathrm{O}$ direito à liberdade, por mais importante que seja para a humanização, e, talvez, até por isso mesmo, nunca pode ser absoluto: é um direito relativo e, muitas vezes, podem-se observar conflitos de direitos, envolvendo também a liberdade.

Luiz David Araújo e Vidal Serrano Nunes Júnior definem o que vêm a ser os direitos fundamentais:

(...) afigura-se como o único apto a exprimir a realidade jurídica precitada, pois que, cogitando-se de direitos, alude-se a posições subjetivas do indivíduo, reconhecidas em determinado sistema jurídico e, desta feita, passíveis de reivindicação judicial. O adjetivo "fundamentais" traduz, por outro ponto, a inerência desses direitos à condição humana, exteriorizando, por conseguinte, o acúmulo evolutivo dos níveis de alforria do ser humano (ARAÚJO; NUNES JÚNIOR, 2017, p. 152).

Os autores nos ensinam, também, que os direitos fundamentais pertencem a uma categoria jurídica construída, constitucionalmente, para a proteção da dignidade humana, em todas as suas dimensões. São multifacetados e protegem o ser humano em sua liberdade - direitos civis e garantias individuais -, em suas necessidades - direitos econômicos, sociais e culturais - e na preservação da espécie - direitos à fraternidade e à solidariedade - (ARAÚJO; NUNES JÚNIOR, 2017, p. 153).

Muitos doutrinadores sustentam que o direito à vida, do qual o direito à saúde é derivado, é um pressuposto inafastável para o pleno e digno desenvolvimento da personalidade. Müller (2014) quando ressalta que "o direito à saúde é o umbral do direito à vida e, sem dúvida, um dos pressupostos básicos da dignidade e do desenvolvimento da pessoa. É um direito natural, porque tem sua origem nas leis universais da natureza, como a conservação das espécies". 
A autora ainda reitera que a defesa da saúde "é uma consequência da proteção do direito à vida, valor supremo num Estado de Direito, que, dentre as prerrogativas humanas, ocupa o primeiro posto" (MÜLLER, 2014).

A autora ressalta, ainda, que "o direito fundamental que protege a vida digna é o direito à vida, que compreende um sem-número de facetas, como o direito à saúde e o direito a uma vida decente". A mesma completa, ao afirmar que: "o direito à saúde é um direito derivado do direto personalíssimo à vida, a saúde é uma situação, estado e uma dinâmica que permite ao ser humano estar ótimo com seu corpo, mente e espírito, e o desenvolvimento de seu projeto de vida individual e social" (MÜLLER, 2014).

\section{DIREITO À SAÚDE COMO DIREITO HUMANO E FUNDAMENTAL}

O direito à saúde, como bem jurídico indissoluvelmente ligado à vida, pode ser considerado como direito coletivo ou direito de incidência coletiva, no rol dos chamados direitos de terceira dimensão ou geração. Esses direitos abrangem desde pequenos grupos, até toda a sociedade. Pode-se falar em direito de solidariedade, uma visão mais ampla e profunda do direito à proteção e promoção da saúde integral dos cidadãos e, ainda, o direito à atenção sanitária, em condições de real igualdade.

Assim, pode-se falar em direitos sociais e, também, direitos de solidariedade, que implicam o exercício pleno dos direitos de interesse comum, que seria mais do que a somatória de vários direitos individuais, os chamados de interesses difusos, que inclui o direito a um meio ambiente são, equilibrado, apto ao desenvolvimento do ser humano e o direito à paz. No prefácio do Relatório sobre Desenvolvimento Humano 2000 do PNUD, encontramos o alerta:

[...] não basta que os países outorguem direitos econômicos e sociais somente na teoria. Não se pode criar, por meio da legislação, boa saúde e emprego. É necessária uma economia suficientemente sólida para oferecê-los [...] os direitos humanos não são, como se tem sustentado, por vezes, uma recompensa do desenvolvimento, mas fundamentais para alcançá -lo (MÜLLER, 2014). 
O direito à saúde, hoje, apresenta um conceito muito mais amplo, que se traduz pelo direito a uma melhor qualidade de vida (MÜLLER, 2014), e não somente o fato de não estar doente, e é considerado um direito de natureza prestacional, um direito ao acesso da população a serviços e produtos de saúde, com qualidade e quantidade suficientes, para uma proteção e preservação da saúde adequadas (MÜLLER, 2014). Pode-se incluir, no conceito a uma melhor qualidade de vida, o direito à felicidade, fundamento recorrente em várias decisões judiciais contemporâneas.

Alguns autores consideram o direito à saúde como direito humano fundamental individual, o bem jurídico é a saúde individual, relação médico/paciente, direito de primeira geração ou dimensão; outros, como direito humano fundamental social, direito de segunda geração ou dimensão; outros, direito à solidariedade, direito de terceira geração ou dimensão; outros ainda, de quarta geração, como direito de proteção do futuro, como nos mostra Müller (2014).

O conceito de saúde, antes com foco apenas na ausência de enfermidade, um conceito negativo, evoluiu para um bem-estar físico, psíquico, social e cultural, assim considerado pelos próprios documentos e tratados internacionais e pela própria OMS, ainda conforme Müller (2014).

A autora resume que se pode responder à pergunta inicial sobre se a saúde seria um direito de quarta geração, afirmando que, na atualidade, existe um direito da saúde - como direito individual, como direito social, como direito solidário, e como direito à saúde das pessoas futuras, que coexistem e não se anulam, a saber:

Direito da saúde individual - bem jurídico é a saúde individual, marco da relação médico/paciente (primeira geração). Direito da saúde social - bem jurídico social, marco das prestações assistenciais, sanitárias e farmacológicas por parte do Estado, de natureza prestacional (segunda geração).

Direito da saúde solidário - bem jurídico coletivo, marco das políticas nacionais da saúde pública de curto e médio prazo, que impõe ao Estado a instrumentalização de políticas e ações concretas (terceira geração).

Direito da saúde das pessoas futuras - bem jurídico coletivo, marco das políticas de médio e longo prazo, que im- 
põe ao Estado políticas e ações concretas (quarta geração) (MÜLLER, 2014).

Para Müller (2014), portanto, o direito à saúde é um direito multidimensional, já que seu pleno exercício implica a realização de vários níveis (de direitos) relacionados à qualidade de vida física, mental, etc. Por isso, é um direito que se tende a ampliar, pois a evolução tecnocientífica vem elevando os patamares mínimos de exigibilidade para o que se deva considerar uma vida digna para todo cidadão. O direito à saúde, segundo a autora, também abrange a saúde individual e a coletiva e, por essa razão, deva ser considerada como bem social, bem de toda a humanidade, direito constitucional fundante e personalíssimo, na medida em que possibilita a existência de todos os demais direitos, além de prestacional, já que é uma prestação exigível em face do Estado.

No Pacto Internacional de Direitos Econômicos, Sociais e Culturais, Observação geral n. ${ }^{\circ} 14$, de 2000, pode-se destacar o conceito do direito à saúde, conforme aquele documento:

A saúde é um direito humano fundamental e indispensável para o exercício dos demais direitos humanos. Todo ser humano tem direito a desfrutar do mais alto nível possível de saúde que lhe permita viver dignamente. A efetividade do direito à saúde pode ser alcançada mediante numerosos procedimentos complementares, como a formulação de políticas em matéria de saúde, a aplicação dos programas de saúde elaborados pela Organização Mundial da Saúde (OMS) ou a adoção de instrumentos jurídicos concretos. Além disso, o direito à saúde inclui determinados componentes, aplicáveis em virtude da lei (OMS, 2014).

No preâmbulo da Constituição da Organização Mundial de Saúde (OMS), os Estados partes declaram que, em conformidade com a Carta das Nações Unidas, os princípios elencados naquele documento são básicos para a felicidade, as relações harmoniosas e a segurança de todos os povos, além de definirem a saúde como: 
(...) um estado de completo bem-estar físico, mental e social, e não somente a ausência de afecções ou enfermidades. $\mathrm{O}$ gozo do grau máximo de saúde que se possa alcançar é um dos direitos fundamentais de todo ser humano sem distinção de raça, religião, ideologia política ou condição econômica ou social. A saúde de todos os povos é uma condição fundamental para atingir a paz e a segurança, e depende da mais ampla cooperação das pessoas e dos Estados. Os resultados alcançados pelo Estado no fomento e proteção da saúde são valiosos para todos. A desigualdade dos diversos países, relativa ao fomento da saúde e ao controle das enfermidades, sobretudo as transmissíveis, constitui um perigo comum. $\mathrm{O}$ desenvolvimento saudável da criança é de importância fundamental; a capacidade de viver em harmonia num mundo que muda constantemente é indispensável para esse desenvolvimento. A extensão dos benefícios dos conhecimentos médicos, psicológicos e afins a todos os povos é essencial para alcançar o mais alto grau de saúde. Uma opinião pública bem informada e uma cooperação ativa por parte do público são de importância capital para o aperfeiçoamento da saúde do povo. Os governos têm responsabilidade pela saúde de seus povos, que só pode ser cumprida mediante a adoção de medidas sanitárias e sociais adequadas (OMS, 2014).

A Constituição (OMS) foi adotada pela Conferência Sanitária Internacional, celebrada em Nova York, de 19 de junho a 22 de julho de 1946, assinada em 22 de julho de 1946 pelos representantes de 61 Estados (Off. Rec. WldHlth Org.; Actes off. Org. mond. Santé, 2, 100), e entrou em vigor em 7 de abril de 1948. As reformas adotadas pela 26.a, 29.a, 39.a e 51.a Assembleias Mundiais da Saúde (resoluções WHA26.37, WHA29.38, WHA39.6 y WHA51.23), que entraram em vigor em 3 de fevereiro de 1977, em 20 de janeiro de 1984, em 11 de julho de 1994 e em 15 de setembro de 2005, respectivamente, incorporaram-se ao texto. A finalidade (Capítulo I - art. 1) da Organização Mundial da Saúde (OMS) é alcançar o mais alto grau possível de saúde para todos os povos (OMS, 2014). 


\section{O DIREITO À SAÚDE NA LEGISLAÇÃO PÁTRIA E INTERNACIONAL}

No Brasil, a Constituição vigente contempla o direito à saúde como direito humano fundamental social, no art. $6 .^{\circ}$, que assim dispõe:

Artigo 6 da Constituição Federal de 1988: São direitos sociais a educação, a saúde, a alimentação, o trabalho, a moradia, o transporte, o lazer, a segurança, a previdência social, a proteção à maternidade e à infância, à assistência aos desamparados, na forma desta Constituição (VADE MECUM, 2017).

No mesmo diploma legal, no Título VIII - Da Ordem Social, no Capítulo II, Da Seguridade Social, definida, no art. 194, como "um conjunto integrado de ações de iniciativa dos Poderes Públicos e da sociedade, destinadas a assegurar os direitos relativos à saúde, à previdência e à assistência social", temos, do art. 196 ao art. 200, diretrizes e princípios sobre a saúde. Convém destacar o art. 193, que afirma que a ordem social tem, como base, o primado do trabalho, e, como objetivos, o bem-estar e a justiça sociais (Brasil, 1988)

O art. 196 determina que a saúde é direito de todos e dever do Estado, "garantido mediante políticas sociais e econômicas que visem à redução do risco da doença e de outros agravos e ao acesso universal igualitário às ações e serviços para sua promoção, proteção e recuperação", mesma redação, ipsis literis, do art. $2^{\circ} \S 1^{\circ}$ da Lei 8.080/90 (BRASIL, 1990).

Ainda no Título VIII - Da Ordem Social, no Capítulo VI, Do Meio Ambiente, no art. 225, fica clara a ligação inexorável entre a saúde e a qualidade do meio ambiente:

Artigo 225 da Constituição Federal de 1988: Todos têm direito ao meio ambiente ecologicamente equilibrado, bem de uso comum do povo e essencial à sadia qualidade de vida, impondo-se ao Poder Público e à coletividade o dever de defendê-lo a preservá-lo para as presentes e futuras gerações (BRASIL, 1988)

Outro documento legal, a supramencionada Lei 8.080/90, que surgiu a partir da norma constitucional, define, logo no Título I, art. $2^{\circ}$ : "saúde é um 
direito fundamental do ser humano, devendo o Estado prover as condições indispensáveis ao seu pleno exercício". Cabe ressaltar que o dever do Estado não exclui o das pessoas, seja da família, seja das empresas, seja da sociedade (BRASIL, 1990).

No art. $3^{\circ}$, a Lei 8.080/90 dispõe que os níveis de saúde expressam a organização social e econômica do País, tendo a saúde como determinantes e condicionantes, entre outros, a alimentação, a moradia, o saneamento básico, o meio ambiente, o trabalho, a renda, a educação, a atividade física, o transporte, o lazer e o acesso aos bens e serviços essenciais, o que mostra a relevância de todos esses fatores para a sadia qualidade da saúde e para o bem-estar físico e mental do cidadão (BRASIL, 1990). É o que se reafirma no parágrafo único do artigo em apreço:

Art. 3 - Dizem respeito também à saúde as ações que, por força do disposto no artigo anterior, se destinam a garantir às pessoas e à coletividade condições de bem-estar físico, mental e social (BRASIL, 1990).

O grau de desenvolvimento social, cultural e econômico do Brasil passa, necessariamente, pelo nível de atendimento à saúde e ao bem-estar físico e mental de seus cidadãos, assim também a imagem do País, no cenário internacional.

$\mathrm{Na}$ Introdução do Folheto Informativo $n^{\circ} 31$, dedicado ao direito à saúde, editado pela Organização Mundial da Saúde (OMS), em parceria com o Alto Comissariado para os Direitos Humanos da Organização das Nações Unidas (ONU), já há clareza sobre a alta relevância do tema, segundo o entendimento dos organismos internacionais (OMS, 2014b).

Esse documento considera que a saúde deve ser motivo de preocupação cotidiana. Independentemente da idade, gênero, condição socioeconômica ou origem étnica, a saúde é o bem mais fundante e precioso que possuímos.

A falta de saúde pode impedir a ida à escola ou ao trabalho, levar a deixar de cumprirem-se as responsabilidades familiares ou de participar-se plenamente das atividades da comunidade. Por isso mesmo, todos sempre estão dispostos a fazer muitos sacrifícios, para garantir uma vida melhor e mais saudável. Quando falamos de bem-estar, pensa-se em saúde. O direito à saú- 
de, segundo a OMS e a ONU, é parte fundamental dos direitos humanos e do que se entende por dignidade humana.

O direito a desfrutar do nível mais alto possível de saúde física e mental não é novidade. No plano internacional, proclamou-se, pela primeira vez, na Constituição da Organização Mundial da Saúde (OMS), de 1946, em cujo preâmbulo se define a saúde como "um estado de completo bem-estar físico, mental e social, e não somente a ausência de afecções e enfermidades", complementando que "o gozo do grau máximo de saúde que se possa alcançar é um dos direitos fundamentais de todo ser humano, sem distinção de raça, religião, ideologia política ou condição econômica ou social", como já citado anteriormente (OMS, 2014).

Na Declaração Universal de Direitos Humanos, de 1948, também se menciona a saúde como parte do direito a um nível de vida adequado (art. 25). $\mathrm{O}$ direito à saúde também foi reconhecido como direito humano pelo Pacto Internacional de Direitos Econômicos, Sociais e Culturais, de 1966, supracitado (ONU, 1948).

Desde então, reconheceu-se o direito à saúde ou os direitos correlatos, como, por exemplo, o direito à atenção médica, em outros tratados internacionais de direitos humanos. O direito à saúde é importante para todos os Estados, que ratificaram ao menos um tratado em que se reconhece esse direito. Além disso, os Estados se comprometeram a protegê-lo, no marco de declarações internacionais, leis e políticas nacionais e conferências internacionais.

Para a OMS e a ONU, segundo o Folheto Informativo $n^{\circ} 31$, o direito à saúde é um direito inclusivo, pois, além de estar relacionado ao acesso à atenção sanitária e a construção de hospitais, compreende um amplo conjunto de fatores que podem contribuir para uma vida saudável (OMS, 2014b).

O Comitê de Direitos Econômicos, Sociais e Culturais, que é o órgão encarregado de fazer cumprir o Pacto Internacional de Direitos Econômicos, Sociais e Culturais, denomina-os de fatores determinantes básicos da saúde: água potável e condições sanitárias adequadas; alimentos aptos para o consumo; nutrição e moradia adequadas; condições de trabalho e meio ambiente saudáveis; educação e informação sobre questões relacionadas com a saúde; igualdade de gênero. 
Segundo a OMS e a ONU, o direito à saúde abrange, também, o direito de não ser submetido a tratamento médico sem o próprio consentimento, experimentos e investigações médicas ou esterilização forçada, e de não ser submetido a tortura ou outros tratamentos ou penas cruéis, desumanos ou degradantes.

Ainda segundo tais documentos, o direito à saúde ainda inclui outros direitos implícitos: o direito a um sistema de proteção da saúde, que dê a todos iguais oportunidades para desfrutar do mais alto nível possível de saúde; o direito à prevenção e ao tratamento das enfermidades e a luta contra elas; o acesso a medicamentos essenciais; a saúde materna, infantil e reprodutiva; o acesso igualitário e oportuno (tempestivo) aos serviços de saúde básicos; o acesso à educação e à informação sobre questões relacionadas com a saúde; a participação da população, no processo de adoção de decisões sobre questões relacionadas com a saúde, no âmbito comunitário e nacional.

A OMS e a ONU destacam, ainda, no Folheto Informativo ${ }^{\circ} 31$, que se devem facilitar o acesso de todos a serviços, bens e instalações de saúde, sem discriminação. Todos os serviços, bens e instalações devem estar disponíveis e ser acessíveis, aceitáveis e de boa qualidade.

Completam OMS e ONU que o direito à saúde não é o mesmo que direito a estar saudável. O Estado não tem o dever de garantir boa saúde, pois ela depende de vários fatores que não estão sob seu controle, como, por exemplo, a estrutura biológica e a situação socioeconômica das pessoas.

O direito à saúde, garantido pelo Estado, deve ser considerado como o desfrutar de um conjunto de bens, instalações, serviços e condições necessários para alcançá-la. Por isso, é mais preciso defini-lo como o direito ao mais alto nível possível de saúde física e mental, do que como o direito incondicional de estar saudável.

O direito à saúde, também, não é só um objetivo programático a longo prazo. Apesar das limitações de recursos, algumas obrigações têm efeito imediato, como garantir o direito à saúde sem qualquer discriminação e elaborar leis e planos de ação específicos, ou outras medidas análogas.

A OMS e a ONU ressaltam que as dificuldades econômicas de um país não o eximem da obrigação de adotar medidas que garantam o desfrute do di- 
reito à saúde. Os direitos humanos são interdependentes e indivisíveis e estão relacionados entre si, o que significa que o não reconhecimento do direito à saúde pode impedir o exercício de outros direitos humanos, como, por exemplo, o direito à educação e ao trabalho, e vice-versa.

A OMS e a ONU, no folheto informativo $n^{\circ} 31$ (OMS, 2014b), alertam para os vínculos entre o direito à saúde e o direito à água, pois a má saúde está associada com a ingestão de água não potável ou o contato com ela, a falta de água limpa (o que está relacionado com uma higiene inadequada), a falta de serviços de saneamento, e uma má gestão dos recursos e os sistemas hídricos, em particular na agricultura.

A maioria das enfermidades diarreicas que se registram no mundo pode atribuir-se à agua insalubre e a um saneamento e higiene inadequados. Em 2002, enfermidades diarreicas atribuíveis a esses três fatores foram a causa de $2,7 \%$, aproximadamente, das mortes em todo o mundo - 1,5 milhões (OMS, 2007).

\section{TRATADOS, PACTOS E CONVENÇÕES INTERNACIONAIS DE DIREITOS HUMANOS EM QUE SE RECONHECE O DIREITO À SAÚDE}

A Convenção Americana de Direitos Humanos, subscrita em 22.11.69, em San José de Costa Rica, vigente desde 18.07.78, em seu art. 26, estabelece o princípio da progressividade e proíbe o retrocesso, em matéria de direitos econômicos, sociais e culturais, como o direito à saúde.

A Declaração Universal dos Direitos Humanos assegura, em seu art. 25.1, o direito de toda pessoa à saúde e ao bem-estar.

A Convenção Internacional sobre a Eliminação de todas as Formas de Discriminação Racial, 1965, no art. 5, e) IV), também prevê o direito à saúde como direito humano e social.

O PIDESC, no Parágrafo $2^{\circ}$ do artigo 10, dispõe que se deve conceder especial proteção às mães durante certo período de tempo razoável, antes e depois do parto. Durante esse período, às mães que trabalhem fora deve-se conceder licença remunerada com prestações adequadas, pela seguridade social. 
Cabe acrescentar que a Assembleia Geral da OEA elaborou um estudo intitulado "Indicadores do Progresso para Medição de Direitos Contemplados no Protocolo de San Salvador", cujo objetivo principal é medir o cumprimento progressivo dos direitos econômicos, sociais e culturais, contidos no Protocolo de San Salvador.

Na Convenção sobre a eliminação de todas as formas de discriminação contra a mulher, 1979, nos arts. 11, 1) f), 12 e 14, 2) b)

O Pacto Internacional de Direitos Econômicos, Sociais e Culturais, 1966, no art. 12, garante o direito à saúde, como direito humano, dentre os direitos sociais.

\section{Artigo 12:}

1. Os Estados Partes adotarão todas as medidas apropriadas para eliminar a discriminação contra a mulher na esfera da atenção médica, a fim de assegurar, em condições de igualdade entre homens e mulheres, o acesso a serviços de atenção médica, inclusive os que se referem ao planejamento familiar.

2. Sem prejuízo ao disposto no parágrafo $1^{\circ}$ supra, os Estados Partes garantirão à mulher serviços apropriados em relação à gravidez, ao parto e ao período posterior ao parto, proporcionando serviços gratuitos quando for necessário, e lhe assegurarão uma nutrição adequada, durante a gravidez e o aleitamento.

A violência contra a mulher está relacionada com os direitos da mulher e com o direito à saúde, e é a causa do maior número de danos físicos e psicológicos ou de sofrimento entre as mulheres, assim como a violação de seu direito à saúde.

O Comitê sobre a Eliminação da Discriminação contra a Mulher requer que os Estados promulguem e apliquem leis e políticas que protejam as mulheres e as meninas da violência e dos maus tratos e habilitem serviços de saúde física e mental apropriados. Também deve capacitar o pessoal de saúde para que saiba detectar e enfrentar as consequências que a violência contra a mulher tem sobre a sua saúde, ao mesmo tempo que proibir a mutilação genital feminina.

Os Estados devem atuar com a devida diligência para prevenir, investigar e judicializar atos de violência desse tipo, perpetrados por agentes estatais 
ou por particulares. As mulheres que hajam sofrido qualquer forma de violência têm direito a reparação e reabilitação adequadas que abranjam sua saúde física e mental.

Na Convenção sobre os Direitos da Criança, 1989, no art. 24, há previsão da garantia ao direito à saúde.

Na Convenção Internacional sobre a proteção dos direitos de todos os trabalhadores migratórios e de seus familiares, 1990, nos arts. 28, 43 e) e $45 \mathrm{c}$ ), podemos também encontrar a garantia do direito humano social à saúde.

A Convenção sobre os direitos das pessoas com deficiência, 2006, no art. 25, dispõe sobre a proteção do direito à saúde.

Na Declaração Final da Conferência Internacional de Assistência Primária à Saúde, realizada na cidade de Alma-Ata (atual Cazaquistão), em 1978, promovida pela OMS, confirma-se a função decisiva da atenção primária de saúde, que se orienta para os principais problemas de saúde da comunidade e presta serviços de promoção, prevenção, tratamento e reabilitação necessários para resolver esses problemas (art. VII). Nela se destaca que o acesso à atenção primária de saúde é a chave para alcançar um nível de saúde que permita a todas as pessoas levar uma vida social e economicamente produtiva (art. V) e contribuir para o desfrute do mais alto nível possível de saúde.

Nas Constituições Nacionais, também são diversos os exemplos de acolhimento da saúde como direito fundamental. A Constituição Sul Africana (1996) dispõe, no Capítulo II, art. 27: atenção sanitária, alimentos, água e seguridade social -

1) Todas as pessoas têm direito a:

a) Serviços de saúde, incluída a saúde reprodutiva;

b) Alimentos e água suficientes;

[...]

2) O Estado deve adotar medidas legislativas e outras razoáveis, dentro dos limites dos recursos disponíveis, para alcançar a progressiva realização de cada um desses direitos.

3) Não se poderá negar a ninguém tratamento médico de urgência.

A Constituição da Índia (1950), na Parte IV, art. 47, prevê o dever do Estado de elevar o nível de nutrição, o nível de vida e melhorar a saúde 
pública: “O Estado considerará a elevação do nível de nutrição, o nível de vida de sua população e a melhoria da saúde pública uma de suas obrigações primordiais..."

A Constituição do Equador (1998), na Seção IV: Direitos econômicos, sociais e culturais, art. 32, dispõe que “o Estado garantirá o direito à saúde, sua promoção e proteção, por meio do desenvolvimento da segurança alimentar, a provisão de água potável e saneamento básico, o fomento de ambientes saudáveis no âmbito familiar, laboral e comunitário, e a possibilidade de acesso permanente e ininterrupto a serviços de saúde, conforme os princípios de equidade, universalidade, solidariedade, qualidade e eficiência".

A Constituição da Argentina consagrou o direito à saúde no art. 42, que dispõe "os consumidores e usuários de bens e serviços têm direito, na relação de consumo, à proteção de sua saúde, seguridade e interesses econômicos; a uma informação adequada e verdadeira; à liberdade de escolha e a condições de trato equitativo e digno (...)".

A Constituição da Bolívia prevê o direito à saúde no art. 35, que expressa "o Estado, em todos os níveis, protegerá o direito à saúde, promovendo políticas públicas orientadas a melhorar a qualidade de vida, o bem-estar coletivo e o acesso gratuito da população aos serviços de saúde. O sistema de saúde é único e inclui a medicina tradicional das nações e povos indígenas originários e camponeses".

Ainda mencionamos as seguintes Constituições, que preveem, em seus textos, a garantia do direito à saúde, como direito humano e fundamental - a Constituição da Colômbia, no art. 49; a Constituição da Costa Rica, no art. 46; a Constituição do Chile, no art.19, inc. IX; a Constituição de Salvador, no art. 65; a Constituição da Guatemala, nos arts. 93 e 94; a Constituição do Haiti, no art. 19; a Constituição de Honduras, no art. 145; a Constituição do México, no art. 40; a Constituição da Nicarágua, no art. 59; a Constituição do Panamá, no art. 109; a Constituição do Paraguai, no art. 68; a Constituição do Peru, no art. 70; a Constituição da República Dominicana, no art. 61; a Constituição do Uruguai, no art. 44; a Constituição da Venezuela, no art. 83.

Os padrões do Direito Internacional de Proteção dos Direitos Humanos constituem elementos, a partir dos quais é possível delimitar o conteúdo essen- 
cial dos direitos, que são fundamentais para compreender o direito à saúde. Esse marco constitui o ponto de partida para o delineio, seguimento e avaliação das políticas públicas e permite demonstrar até que ponto se cumprem as obrigações que emergem dos tratados internacionais.

\section{INTERPRETAÇÃO E CASOS CONCRETOS}

A Corte Suprema de Justiça da Nação (CSJN) estabeleceu a proeminência dos tratados sobre as leis (caso "Ekmekdkjian"). A interpretação da Convenção Americana sobre Direitos Humanos deve guiar-se pela jurisprudência da Corte Interamericana de Direitos Humanos (causa "Mazzeo").

No caso "Carranza Latrubesse", o Alto Tribunal enfatizou que, em virtude do princípio da boa-fé, princípio do direito internacional público, se um Estado assina e ratifica um tratado internacional, especialmente se tratar-se de direitos humanos, como é o caso da $\mathrm{CADH}$, tem obrigação de realizar seus melhores esforços para aplicar as recomendações do órgão de proteção.

\subsection{Paradigma interpretativo da OEA}

Convém ressaltar que a OMS não possui mecanismos de proteção diretamente relacionados à responsabilização por danos à saúde. Hoje, somente a OEA e a ONU têm soluções práticas para os problemas públicos da saúde, chamados de mecanismos de constrangimento. A OMS só possui mecanismos de cooperação internacional.

No âmbito da OEA, ganham destaque os casos julgados pela Corte Interamericana de Direitos Humanos da OEA, entre os quais destacamos os seguintes.

\subsection{O caso Ximenes Lopes X Brasil (2006)}

Demanda da CIDH ante a Corte IDH por suposta violação dos direitos à vida, integridade pessoal, garantias judiciais e proteção judicial (obrigação geral de respeitar os direitos) - arts. 1.1, 4, 5, 8, 25, do citado instrumento inter- 
nacional - em prejuízo do Sr. Ximenes Lopes, deficiente mental, hospitalizado em condições desumanas e degradantes, com violação à sua integridade física pelos trabalhadores da casa de repouso em que habitava e por sua posterior morte dentro da instituição, onde se realizava seu tratamento psiquiátrico, três dias depois de sua internação.

Na demanda, a Comissão solicitou à Corte IDH que declarasse a responsabilidade do Estado brasileiro pelos atos praticados e pela particular situação de vulnerabilidade em que se encontram as pessoas deficientes mentais, em relação à especial obrigação do Estado de proteger as pessoas que se encontram sob os cuidados de centros de saúde que funcionam dentro do Sistema Único de Saúde - SUS.

A Corte IDH concluiu que o Brasil havia violado o direito à vida e à integridade pessoal, em prejuízo de Ximenes Lopes e, entre outras medidas, determinou ao Estado desenvolver um programa de formação e de capacitação para o pessoal médico sobre os princípios que devem reger o trato das pessoas que padecem de incapacidade mental, conforme os padrões internacionais relativos à matéria.

O caso Albán Cornejo e outros X Equador (2007). Demanda ante a Corte por parte da CIDH contra o Equador. Laura Susana Albán Cornejo deu entrada no Hospital Metropolitano, instituição de saúde privada em Quito, com quadro clínico de meningite bacteriana. Com fortes dores, foi-lhe ministrada, pelo médico residente, uma injeção de morfina. A paciente veio a falecer, supostamente devido à aplicação da injeção.

A Corte resolveu declarar, internacionalmente, o Estado como responsável pela violação do direito à integridade pessoal, em prejuízo dos pais de Laura, e determinou ao Equador que realizasse um programa para a formação e a capacitação dos operadores de justiça e profissionais da saúde, sobre os normativos que o Equador implementou relativos aos direitos dos pacientes e a punir os responsáveis por seu descumprimento.

O caso Suárez Peralta X Equador (2013). Melba del Carmen Suárez Peralta - falta de proteção judicial no processo penal contra os supostos responsáveis da má prática médica que afetou a vítima.

CIDH submeteu o caso ante a Corte IDH - a Corte considerou o Estado 
responsável, internacionalmente, por violação do dever de garantia ao direito à integridade pessoal, reconhecido no art. 5.1 da Convenção, em relação com o art. 1.1 do citado instrumento, em prejuízo de Melba, sem declarar a violação específica do direito à saúde.

Os casos supracitados contribuíram para o reconhecimento do direito à saúde, por declarar, indiretamente, a responsabilidade do Estado, internacionalmente, pelo descumprimento dos deveres estatais, por omissão na fiscalização e na supervisão estatais das instituições de saúde, públicas ou privadas, onde as vítimas receberam tratamento médico prejudicial.

Para Furfaro (2014), os três pronunciamentos relativos a esses casos apresentam falha, por não haver sido declarada a violação específica do direito à saúde, de maneira individualizada e autônoma. Embora esse direito esteja transversal, nos três precedentes, e que, de fato, tenha sido afetado o direito à saúde, a Corte IDH decidiu não enfrentar análise específica sobre este direito. $\mathrm{O}$ autor vê essa atitude como miopia da Corte.

A posição do Comitê DESC do Sistema Universal de Proteção dos Direitos Humanos é diferente da posição da Corte, segundo Furfaro (2014), posicionando-se claramente sobre a "atenção primária de saúde essencial, obrigação em virtude do Pacto" (FURFARO, 2014).

Desde seu primeiro pronunciamento indireto sobre o direito à saúde, no caso Ximenes Lopes X Brasil, até sua mais recente jurisprudência sobre a matéria, no caso Suárez Peralta X Equador, a própria Corte IDH tem explicado a estreita relação do dever de garantia do art. 1.1 com o art. 5.1 da CADH. A Corte tem enfatizado, reiteradamente, que "(...) o direito à integridade pessoal está direta e imediatamente vinculado com a atenção à saúde humana". Por isso, o Tribunal tem destacado que a falta de atenção médica adequada pode levar à violação do art. 5.1 da CADH (FURFARO, 2014).

Segundo Furfaro (2014), a Corte IDH tem determinado reiteradamente que “ (...) a proteção do direito à integridade pessoal supõe a regulação dos serviços de saúde no âmbito interno, assim também a implementação de mecanismos para tutelar a efetividade de tal regulação", como uma das implicações do padrão de proteção do direito à saúde, em conexão com o direito à integridade pessoal. 
Na visão do autor, o Tribunal Interamericano tem decidido que, para cumprir a obrigação de garantir o direito à integridade pessoal em relação com o direito à saúde, os Estados devem estabelecer um marco normativo adequado, que regule a prestação de serviços de saúde, implementando-se padrões de qualidade para as instituições públicas e privadas, que permitam prevenir ameaças de violação à integridade pessoal.

O Estado deve prever mecanismos de supervisão e fiscalização estatal das instituições de saúde, como procedimentos de tutela administrativa e judicial para o prejudicado, cuja efetividade dependerá das ações da administração competente.

\section{CONSIDERAÇÕES FINAIS}

Esse trabalho se propôs a conceituar direitos humanos, direitos fundamentais, direito à saúde, como direito humano e fundamental, e sua relação com o direito à vida, direito à integridade física e a um meio ambiente equilibrado e à sustentabilidade.

Os direitos fundamentais fazem parte das necessidades humanas básicas, a partir dos quais advêm todos os demais direitos. Uma sociedade desenvolvida e civilizada só pode existir a partir do pleno exercício dos direitos humanos fundamentais.

O direito à vida é o principal direito humano fundamental e dele é corolário direto o direito à saúde, o direito à integridade física e a um meio ambiente equilibrado e à sustentabilidade.

Não se pode sobrepor o direito à integridade física ao direito à saúde, como ocorreu nos pronunciamentos da Corte, em relação aos três casos emblemáticos citados nesse trabalho, em que a instituição evitou enfrentar, individualizadamente, o direito à saúde.

Se a própria Corte Interamericana admite a falta de hierarquia entre os direitos humanos fundamentais civis e políticos, em relação aos direitos econômicos, sociais e culturais, não há que se falar em minimizar a importância do direito à saúde, nem que se precise valer-se de algum direito civil para embasar pronunciamentos sobre lesões ao direito à saúde, dentro do marco dos direitos 
econômicos, sociais e culturais.

Uma vez que o princípio da progressividade e a proibição de regressividade regem os direitos humanos fundamentais econômicos, sociais e culturais, incluído aí o direito à saúde, um direito social, é imprescindível considerar o direito à saúde, individualizada e autonomamente, assim também sua exigibilidade ou judicialidade, no âmbito nacional e internacional.

O Estado deve prever mecanismos de supervisão e fiscalização estatal das instituições de saúde, tanto públicas como privadas, e procedimentos de tutela administrativa e judicial, pois somente com esse controle efetivo, o direito à saúde, direito humano e fundamental, passará a ser levado a sério, de fato e de direito.

\section{REFERÊNCIAS}

ARAÚJO, Luiz Alberto David; NUNES JR., Vidal Serrano. Curso de Direito Constitucional, 21. ${ }^{a}$ edição. São Paulo: Editora Verbatim, 2017.

BRASIL. Constituição da República Federativa do Brasil, de 05 de outubro de 1988. Disponível em http://www.planalto.gov.br/ccivil_03/constituicao/constituicao. htm Acesso em 29 set 2017.

BRASIL. Lei $\mathbf{n}^{0}$ 8.080, de 19 de setembro de 1990. Dispõe sobre as condições para a promoção, proteção e recuperação da saúde, a organização e o funcionamento dos serviços correspondentes e dá outras providências. Disponível em http:/ / www.planalto.gov.br/ccivil_03/leis/L8080.htm Acesso em 29 set 2017.

CANOTILHO, J. J. Gomes. Direito Constitucional. Coimbra: Livr. Almedina, 1991.

FURFARO, Lautaro. Capítulo 2. El derecho a la salud em el Sistema Interamericano de Protección de los derechos humanos. 2014.

MICHAEL, Lothar; MORLOK, Martin. Direitos Fundamentais. São Paulo: Editora Saraiva, 2016 (Série IDP: Linha direito comparado).

MÜLLER, Águeda. Capítulo 2. La salud, um derecho humano. El derecho de la salud e los derechos humanos. 2014. 
OMS. ORGANIZACIÓN MUNDIAL DE LA SALUD. Documentos Básicos. 48. a edición. 2014.

Office de las Naciones Unidas, Alto Comisionado para los Derechos Humanos. El derecho a la Salud. Folheto informativo ${ }^{\circ}{ }^{31 .} 2014 b$.

Organización Mundial de la Salud, Water, sanitation and hygiene: Quantifying the health impact at nacional and local levels in countries with incomplete water supply and sanitation coverage, Environmental Burden of Disease Series, $\mathrm{N}^{\circ}$ 15 - Ginebra, 2007.

ONU. DECLARAÇÃO UNIVERSAL DOS DIREITOS HUMANOS. Assembleia Geral das Nações Unidas em Paris. 10 dez. 1948. Disponível em: http://www.ohchr. org/EN/UDHR/Documents/UDHR_Translations/por.pdf. Acesso em: 26 jun. 2017.

RAMOS, André Carvalho. Curso de Direitos Humanos, 4. ${ }^{\text {a }}$ edição. São Paulo: Saraiva Jur, 2017.

SARLET, Ingo Wolfgang. Teoria Geral dos Direitos Fundamentais in Curso de Direito Constitucional, 6. ${ }^{a}$ edição. São Paulo: Saraiva Jur, 2017. 